Pacific Journal of Mathematics

REGULARITY OF THE BERGMAN PROJECTION IN CERTAIN 


\title{
REGULARITY OF THE BERGMAN PROJECTION IN CERTAIN NON-PSEUDOCONVEX DOMAINS
}

\author{
STEVEN R. BELL
}

\begin{abstract}
Suppose $D$ is a smooth bounded domain contained in $\mathbf{C}^{n}(n \geq 2)$ whose Bergman projection satisfies global regularity estimates, and suppose $K$ is a compact subset of $D$ such that $D-K$ is connected. The purpose of this note is to prove that, under these circumstances, the Bergman projection associated to the domain $D-K$ satisfies global regularity estimates.
\end{abstract}

This result is presently known only in very special cases when both $D$ and $K$ have a particularly simple form. For example, the fundamental paper of Kohn [5] reveals that if $\Omega_{1}$ and $\Omega_{2}$ are two smooth bounded strictly pseudoconvex domains in $\mathbf{C}^{n}(n>2)$ such that $\Omega_{2} \subset \subset \Omega_{1}$, then the $\bar{\partial}$-Neumann problem for the domain $\Omega_{1}-\bar{\Omega}_{2}$ is subelliptic. Kohn's formula, $P=I-\bar{\partial} * N \bar{\partial}$, which relates the Bergman projection $P$ to the $\bar{\partial}$-Neumann operator $N$, shows that the Bergman projection associated to $\Omega_{1}-\bar{\Omega}_{2}$ satisfies global regularity estimates. Recently, Derridj and Fornaess [3] have shown that if $\Omega_{1}$ and $\Omega_{2}$ are two pseudoconvex domains with real analytic boundaries in $\mathbf{C}^{n}$ with $n \geq 3$ and $\Omega_{2} \subset \subset \Omega_{1}$, then the $\bar{\partial}$-Neumann operator for $\Omega_{1}-\bar{\Omega}_{2}$ satisfies subelliptic estimates. Hence, the Bergman projection associated to $\Omega_{1}-\bar{\Omega}_{2}$ satisfies global estimates in this case, also.

In Bell and Boas [2], it is proved that the Bergman projection associated to a smooth bounded complete Reinhardt domain satisfies global regularity estimates. Thus, there are more subtle examples of non-pseudoconvex domains for which regularity of the Bergman projection holds than those addressed by the theorem of the present work. Recently, the techniques used in [2] have been refined by David E. Barrett [1] to prove that the Bergman projection associated to a smooth bounded domain with a Lie group of transverse symmetries satisfies global regularity estimates.

The question as to whether or not the Bergman projection associated to a domain satisfies global regularity estimates is very important in problems relating to boundary behavior of holomorphic mappings (see [2]).

The Bergman projection $P$ associated to a bounded domain $D$ contained in $\mathbf{C}^{n}$ is the orthogonal projection of $L^{2}(D)$ onto $H(D)$, the closed subspace of $L^{2}(D)$ consisting of $L^{2}$ holomorphic functions. The space $C^{\infty}(\bar{D})$ is defined to be the set of functions in $C^{\infty}(D)$, all of whose 
derivatives are bounded functions on $D$. The family of derivative supnorms exhibits the Frechet space topology on $C^{\infty}(\bar{D})$.

We shall say that a bounded domain $D$ satisfies condition $R$ whenever $P$ is a continuous operator from $C^{\infty}(\bar{D})$ to $C^{\infty}(\bar{D})$. We can now state the main result of this paper.

THEOREM. If $D \subset \mathbf{C}^{n}(n \geq 2)$ is a smooth bounded domain which satisfies condition $R$ and $K$ is a compact subset of $D$ such that $D-K$ is connected, then $D-K$ satisfies condition $R$.

Examples of domains for which condition $R$ is known to hold include smooth bounded strictly pseudoconvex domains (Kohn [5]), smooth bounded pseudoconvex domains with real analytic boundaries (Kohn [6], Diederich and Fornaess [4]), and smooth bounded complete Reinhardt domains (Bell and Boas [2]).

Before we prove the theorem, we must define some Sobolev norms and spaces. If $D$ is a smooth bounded domain and $s$ is a positive integer, the space $W^{s}(D)$ is the usual Sobolev space of complex valued functions on $D$ whose distributional derivatives up to order $s$ are contained in $L^{2}(D)$. The Sobolev $s$-norm of a function $u$ is defined via

$$
\|u\|_{s}^{2}=\sum_{|\alpha| \leq s}\left\|\partial^{\alpha} u\right\|_{L^{2}(D)}^{2}
$$

where the symbol $\partial^{\alpha}$ is the standard differential operator of order $\alpha$. If $v \in L^{2}(D)$, we define the negative Sobolev $s$-norm of $v$ via

$$
\|v\|_{-s}=\operatorname{Sup}\left\{\left|\int_{D} v \phi\right|: \phi \in C_{0}^{\infty}(D) ;\|\phi\|_{s}=1\right\} .
$$

If $g \in H(D)$ we define the special Sobolev $s$-norm of $g$ to be

$$
\|g\|_{s}=\operatorname{Sup}\left\{\left|\int_{D} g \bar{h}\right|: h \in H(D) ;\|h\|_{-s}=1\right\} .
$$

REMARK. It is always true that if $D$ is a smooth bounded domain, then there is a constant $C$ such that

$$
\|\|\left\|_{s} \leq C\right\| g \|_{s}
$$

for all $g \in H(D)$. This can be proved using techniques similar to those used in [2]. The reverse inequality $\|g\|_{s} \leq C\|g\|_{s}$ only holds if the Bergman projection associated to $D$ satisfies an estimate of the form $\|P \phi\|_{s} \leq C\|\phi\|_{s}$. The norm \|\|$\|_{s}$ has found fruitful application in the theory of boundary behavior of holomorphic mappings. 
Our main theorem is a relatively simple consequence of the following lemma.

LemMa. Suppose that $D$ is a smooth bounded domain contained in $\mathbf{C}^{n}$ which satisfies condition $R$ and that $s$ is a positive integer. There exists $a$ positive integer $M=M(s)$ and a constant $C=C(s)$ such that

$$
\|g\|_{s} \leq C\|g\|_{s+M}
$$

for all $g$ in $H(D)$.

We shall now prove the theorem, assuming the lemma.

Proof of the Theorem. Let $P$ denote the Bergman projection associated to $D-K$. Let $u$ be a function in $C^{\infty}(\overline{D-K})$. The function $P u$ extends to be holomorphic on all of $D$ by Hartog's theorem. We will prove the theorem by showing that for each positive integer $s$, there are constants $c=c(s)$ and $N=N(s)$ which are independent of $u$ such that

$$
\|P u\|_{W^{s}(D)} \leq c \operatorname{Sup}\left\{\left|\partial^{\alpha} u(x)\right|: z \in D-K ;|\alpha| \leq N\right\} .
$$

Let $s$ be a fixed positive integer, and let $M=M(s)$ be the constant of the lemma associated to $D$ and $s$. According to the lemma, $\|P u\|_{s} \leq$ $C\|\mid P u\|_{s+M}$. Let $g$ be a test function in $H(D)$. To complete the proof of the theorem, we must bound $\left|\int_{D} P u \bar{g}\right|$ by a constant times

$$
\|g\|_{-s-M} \operatorname{Sup}\left\{\left|\partial^{\alpha} u(z)\right|: z \in D-K ;|\alpha| \leq N\right\}
$$

for some integer $N$, where the constant is independent of $g$ and $u$. Let $\Omega$ be a smooth bounded domain such that $K \subset \subset \Omega \subset \subset D$. Now

$$
\int_{D} P u \bar{g}=\int_{D-K} P u \bar{g}+\int_{K} P u \bar{g} .
$$

The second integral in this sum can be ignored for our purposes because $\|g\|_{L^{2}(D-K)} \leq$ (constant) $\|g\|_{-s-M}$ and $\|P u\|_{L^{2}(K)} \leq$ (constant) $\|u\|_{L^{2}(D-K)}$. The first integral can be further decomposed:

$$
\int_{D-K} P u \bar{g}=\int_{D-K} u \bar{g}=\int_{D-\Omega} u \bar{g}+\int_{\Omega-K} u \bar{g} .
$$

Once again, the second integral in the sum can be ignored because $\|g\|_{L^{2}(\Omega)} \leq$ (constant) $\|g\|_{-s-M}$. Thus, it remains only for us to estimate the integral $\int_{D-\Omega} u \bar{g}$.

Let $\partial / \partial n$ denote the normal derivative operator on $b(D-\bar{\Omega})$. If $\psi$ is a function such that $\psi=0=\partial \psi / \partial n$ on $b(D-\bar{\Omega})$, then $\Delta \psi$ is orthogonal to holomorphic functions on $D-\bar{\Omega}$. This can be seen by performing an 
integration by parts. We now solve the following elliptic boundary value problem on $D-\bar{\Omega}$ :

$$
\Delta^{m} \phi=0 \text { on } D-\bar{\Omega}
$$

where $m=s+M+2$, and $\phi$ satisfies the boundary conditions:

$$
\left\{\begin{array}{l}
\phi=\frac{\partial \phi}{\partial n}=0 \\
\Delta \phi=u \\
\left(\frac{\partial}{\partial n}\right)^{t} \Delta \phi=\left(\frac{\partial}{\partial n}\right)^{t} u \text { for } t=1,2, \ldots, m-3
\end{array}\right.
$$

on $b D$ and $b \Omega$.

The solution $\phi$ to this problem is such that $u-\Delta \phi$ belongs to the $W^{s+M}(D-\bar{\Omega})$ closure of $C_{0}^{\infty}(D-\bar{\Omega})$. To complete the proof of the theorem, observe that

$$
\int_{D-\Omega} u \bar{g}=\int_{D-\Omega}(u-\Delta \phi) \bar{g} .
$$

The absolute value of this last integral is less than or equal to

$$
\|u-\Delta \phi\|_{W^{s+M}(D-\Omega)}\|g\|_{-s-M}
$$

Finally, we must estimate $\|u-\Delta \phi\|_{W^{s+M}(D-\Omega)}$. Now, for each positive integer $t$, there is a constant $C_{t}$ which does not depend on $u$ such that $\|\phi\|_{t} \leq C_{t}\|u\|_{t+Q}$ where $Q$ can be taken to be equal to $(m-3)(m+2) / 2$ (see [7]). Hence,

$$
\begin{aligned}
\|u-\Delta \phi\|_{s+M} & \leq C\left(\|u\|_{s+M}+\|\phi\|_{s+M+2}\right) \\
& \leq C \operatorname{Sup}\left\{\left|\partial^{\alpha} u(z)\right|: z \in D-K ;|\alpha| \leq N\right\}
\end{aligned}
$$

where $N=s+M+2+Q$. This completes the proof of the theorem.

The proof of the theorem will be legitimate, once we establish the truth of the lemma.

Proof of the Lemma. Since $P$ maps $C^{\infty}(\bar{D})$ to $C^{\infty}(\bar{D})$ continuously, there is a positive integer $M=M(s)$ such that $\|P \phi\|_{s} \leq$ (constant) $\|\phi\|_{s+M}$ for all $\phi$ in $W^{s+M}(D)$.

Let $\Omega$ be a relatively compact subset of $D$, and let $g$ be a function in $H(D)$. The linear functional $L$ on $H(D)$ defined by

$$
L h=\sum_{|\alpha| \leq s} \int_{\Omega} \partial^{\alpha} h \overline{\partial^{\alpha} g}
$$


is continuous. Hence, There is a function $G$ in $H(D)$ such that $L h=$ $\langle h, G\rangle_{L^{2}(D)}$ for all $h$ in $H(D)$. Now

$$
\|g\|_{W^{s}(\Omega)}^{2}=L g=\langle g, G\rangle_{L^{2}(D)} \leq\|g\|_{s+M}\|G\|_{-s-M} .
$$

The proof of the lemma will be finished when we prove that $\|G\|_{-s-M} \leq$ (constant) $\|g\|_{W^{s}(\Omega)}$ where the constant is independent of $g$ and $\Omega$. Indeed, if $\phi \in C_{0}^{\infty}(D)$, then

$$
\begin{aligned}
\left|\int_{D} G \bar{\phi}\right| & =\left|\int_{D} G \overline{P \phi}\right|=\left|\sum_{|\alpha| \leq s} \int_{\Omega} \partial^{\alpha} g \overline{\partial^{\alpha} P \phi}\right| \leq\|g\|_{W^{s}(\Omega)}\|P \phi\|_{s} \\
& \leq C\|g\|_{W^{s}(\Omega)}\|\phi\|_{s+M} .
\end{aligned}
$$

Hence, $\|g\|_{W^{s}(\Omega)} \leq C\|g\|_{s+M}$. Since the constant $C$ is independent of $g$ and $\Omega$, we obtain that $\|g\|_{s} \leq C\|g\|_{s+M}$.

\section{REFERENCES}

1. D. E. Barrett, Regularity of the Bergman projection on domains with transverse symmetries, Math. Ann., 258 (1982), 441-446.

2. S. Bell and H. Boas, Regularity of the Bergman projection in weakly pseudoconvex domains, Math. Ann., 257 (1981), 23-30.

3. M. Derridj and J. E. Fornaess, Subelliptic estimate for the $\bar{\partial}-$ Neumann problem, Duke Math. J., 48 (1981), 93-107.

4. K. Diederich and J. E. Fornaess, Pseudoconvex domains with real-analytic boundary, Ann. of Math., 107 (1978), 371-384.

5. J. J. Kohn, Harmonic integrals on strongly pseudoconvex manifolds, I and II, Ann. of Math., 78 (1963), 112-148, and Ann. of Math., 79 (1964), 450-472.

6. J. J. Kohn, Subellipticity of the $\bar{\partial}-$ Neumann problem on pseudoconvex domains: sufficient conditions, Acta Math., 142 (1979), 79-122.

7. J. L. Lions and E. Magenes, Non-homogeneous Boundary Value Problems and Applications, Springer-Verlag, Berlin, 1973.

Received August 5, 1981 and in revised form November 11, 1981. Research supported by NSF grant \# MCS 80-17205.

PRINCETON UNIVERSITY

PRINCETON, NJ 08540 



\title{
PACIFIC JOURNAL OF MATHEMATICS EDITORS
}

\author{
Donald BabBitT (Managing Editor) \\ University of California \\ Los Angeles, CA 90024 \\ Hugo Rossi \\ University of Utah \\ Salt Lake City, UT 84112 \\ C. C. Moore and Arthur Ogus \\ University of California \\ Berkeley, CA 94720
}

J. DugundiI

Department of Mathematics

University of Southern California

Los Angeles, CA 90089-1113

R. FINN and H. SAMELSON

Stanford University

Stanford, CA 94305

\section{ASSOCIATE EDITORS}
R. ARENS
E. F. BECKENBACH
B. H. NeUMANN
F. WOLF
K. YosHIDA

(1906-1982)

\section{SUPPORTING INSTITUTIONS}

UNIVERSITY OF ARIZONA

UNIVERSITY OF BRITISH COLUMBIA

CALIFORNIA INSTITUTE OF TECHNOLOGY

UNIVERSITY OF CALIFORNIA

MONTANA STATE UNIVERSITY

UNIVERSITY OF NEVADA, RENO

NEW MEXICO STATE UNIVERSITY

OREGON STATE UNIVERSITY

\author{
UNIVERSITY OF OREGON \\ UNIVERSITY OF SOUTHERN CALIFORNIA \\ STANFORD UNIVERSITY \\ UNIVERSITY OF HAWAII \\ UNIVERSITY OF TOKYO \\ UNIVERSITY OF UTAH \\ WASHINGTON STATE UNIVERSITY \\ UNIVERSITY OF WASHINGTON
}

The Supporting Institutions listed above contribute to the cost of publication of this Journal, but they are not owners or publishers and have no responsibility for its content or policies.

Mathematical papers intended for publication in the Pacific Journal of Mathematics should be in typed form or offset-reproduced (not dittoed), double spaced with large margins. Please do not use built up fractions in the text of the manuscript. However, you may use them in the displayed equations. Underline Greek letters in red, German in green, and script in blue. The first paragraph must be capable of being used separately as a synopsis of the entire paper. In particular it should contain no bibliographic references. Please propose a heading for the odd numbered pages of less than 35 characters. Manuscripts, in triplicate, may be sent to any one of the editors. Please classify according to the scheme of Math. Reviews, Index to Vol. 39. Supply name and address of author to whom proofs should be sent. All other communications should be addressed to the managing editor, or Elaine Barth, University of California, Los Angeles, California 90024.

There are page-charges associated with articles appearing in the Pacific Journal of Mathematics. These charges are expected to be paid by the author's University, Government Agency or Company. If the author or authors do not have access to such Institutional support these charges are waived. Single authors will receive 50 free reprints; joint authors will receive a total of 100 free reprints. Additional copies may be obtained at cost in multiples of 50 .

The Pacific Journal of Mathematıcs is issued monthly as of January 1966. Regular subscription rate: $\$ 132.00$ a year (6 Vol., 12 issues). Special rate: $\$ 66.00$ a year to individual members of supporting institutions.

Subscriptions, orders for numbers issued in the last three calendar years, and changes of address should be sent to Pacific Journal of Mathematics, P.O. Box 969, Carmel Valley, CA 93924, U.S.A. Old back numbers obtainable from Kraus Periodicals Co., Route 100, Millwood, NY 10546.

The Pacific Journal of Mathematics ISSN 0030-8730 is published monthly by the Pacific Journal of Mathematics at P.O. Box 969, Carmel Valley, CA 93924. Application to mail at Second-class postage rates is pend ing at Carmel Valley, California, and additional mailing offices. Postmaster: Send address changes to Pacific Journal of Mathematics, P. O. Box 969, Carmel Valley, CA 93924.

PUBLISHED BY PACIFIC JOURNAL OF MATHEMATICS, A NON-PROFIT CORPORATION

Copyright $(1) 1983$ by Pacific Journal of Mathematics 


\section{Pacific Journal of Mathematics}

\section{Vol. 105, No. $2 \quad$ October, 1983}

Spiros Argyros, On compact spaces without strictly positive measure . . . . . 257

Steven Robert Bell, Regularity of the Bergman projection in certain nonpseudoconvex domains ............................273

Carlos R. Borges and Gary Fred Gruenhage, Sup-characterization of

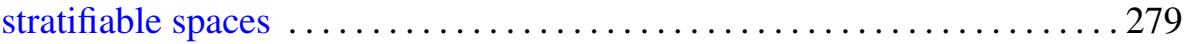

Giuseppe Ceresa and Alberto Collino, Some remarks on algebraic

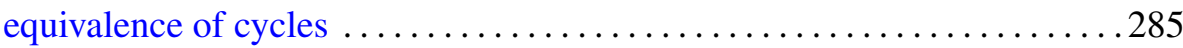

Charles Kam-Tai Chui and Maurice Hasson, Degree of uniform approximation on disjoint intervals ....................... 291

Gary Gundersen, Meromorphic functions that share two finite values with

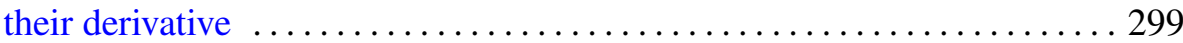

Richard I. Hartley, Lifting group homomorphisms ............... 311

Gerald William Johnson and David Lee Skoug, Notes on the Feynman integral. III. The Schroedinger equation ..................... 321

John Cronan Kieffer, Some topologies on the set of discrete stationary

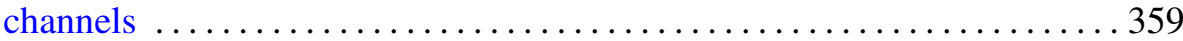

Harald Luschgy and Wolfgang Thomsen, Extreme points in the Hahn-Banach-Kantorovič setting . ............................... 387

Zbigniew Piotrowski, A. Rosłanowski and Brian M. Scott, The pinched-cube topology ................................ 399

Elias Saab and Paulette Saab, A dual geometric characterization of Banach

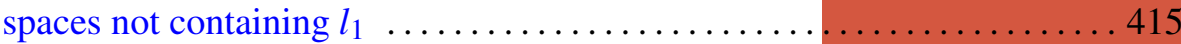

Walter Schachermayer, Norm attaining operators on some classical Banach

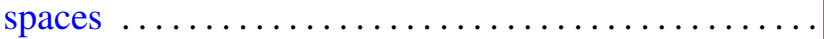

Martin Scharlemann, Essential tori in 4-manifold boundaries

Jacques C. H. Simon, Nonlinear representations of Poincaré group and global solutions of relativistic wave equations ..........

Adrian R. Wadsworth, $p$-Henselian field: $K$-theory, Galois cohomology, and graded Witt rings $\ldots \ldots \ldots \ldots \ldots \ldots \ldots \ldots \ldots$ 